\title{
Legacies of Primary Health Care in an age of Health Sector Reform: Vietnam's Commune Clinics in Transition
}

Scott A. Fritzen

LKY School of Public Policy, National University of Singapore

November 2006

Forthcoming in Social Science \& Medicine

\begin{abstract}
Developing countries that were early, enthusiastic adopters of Primary Health Care often developed an extensive - but eventually dilapidated and under-utilized - network of public clinics at the grassroots. As paradigms and investment patterns of health sector reform have shifted, the question of what role these public clinics can meaningfully play, and how best to revitalize them, has become important in a number of countries. This paper evaluates the strategy taken by, and outcomes of, a major attempt in Vietnam to revitalize the grassroots infrastructure of primary health care against the backdrop of the country's economic transition. The project's substantial supply-side investments in infrastructure led to marginal increases in utilization and the quality of preventive health services provided by the centers. But because the project failed to take adequate stock of broader, public sector-wide trends and reforms over the transition, the investments had little impact on the incentives, accountability patterns and capacities of clinic staff and the local authorities. Such institutional factors are heavily implicated, in Vietnam as elsewhere, in the substantial and often increasing disparities in service access and quality that continue to afflict transitional health sectors.
\end{abstract}

Keywords: primary health care, health sector reform, infrastructure, Vietnam, evaluation, World Bank

\section{Introduction}

Prevailing models for heath sector development in developing countries have shifted over the past three decades, from the initial enthusiasm, mixed success and reported "demise" of Primary Health Care (PHC) to the advent of the market-oriented discourse of 'health sector reform' in recent years (Hall and Taylor, 2003: 17). Meanwhile, the grassroots infrastructure of PHC - notably public clinics sprinkled throughout the countryside of countries which were early, enthusiastic adopters of PHC strategies - have often experienced varying degrees of neglect and 
decay. Yet few convincing, alternative mechanisms have emerged for filling the roles such clinics theoretically and sometimes practically played, such as delivering basic curative services to those for whom private providers are out of geographical or monetary reach and the coordination of preventive health services. Countries that would revitalize this infrastructure must nevertheless do so within a changed institutional context for service provision, one in which the public sector role has often shrunk while the commercialization of health services, and inequalities in service access, have grown.

This paper examines a major attempt in Vietnam to rebuild its extensive but decaying set of commune health centers, and draws lessons from it that may be applicable to other countries experiencing this challenge. The project examined - supported by the country's first healthsector loan from the World Bank following the lifting of the U.S.-led economic embargo in 1994 - unfolded in the midst of the unfolding of the country's dramatic transition from a planned to market economy.

\section{The role of public clinics in shifting health strategies}

The question as to whether it is possible to significantly reduce high levels of infant and maternal mortality in very poor countries has been answered for at least fifteen years. It is a resounding yes. Several low-income countries have succeeded in doing so over the past thirty years even in circumstances where there was no or even negative per capita economic growth and very low government expenditure (Mehrotra, 1997; WHO, 2000). One of the causes for such success is well known to analysts: increasing the access of rural populations to preventive health services, such as child and maternal immunizations, Vitamin A distribution, malarial bednets and facilities for assisted child delivery. These interventions were part of the PHC family of approaches endorsed by the Alma Ata Summit in 1979, which had at its core the assumption that communities should be the organizational basis for delivering health services (Hall and Taylor, 2003).

The community health clinic was an integral part of the PHC model, along with the armies of paraprofessionals - 'barefoot doctors' - who would staff such clinics. Countries such as Vietnam, China, Sri Lanka, Indonesia and Cuba built networks of community health centers that

- though modestly staffed and typically even more modestly equipped - played two essential functions in the theory and practice of PHC health systems (Favin, Parlato \& Kessler, 1984). First, they brought basic curative care within reach of even the poorest residents of rural areas, often using simple - literally prepackaged - technologies such as oral rehydration salts to reduce mortality from diahrreal diseases (Osteria, 1997). Second, the centers served as the forward operating posts for public health delivery systems such as immunizations and the distribution of bednets that played so disproportionate a role in the impact these health systems had on mortality reduction (WHO, 2000). 
At the same time, a number of weaknesses and vulnerabilities in the PHC approach became increasingly apparent over the 1980s and beyond. Some attacked the premise of universality implied by PHC as unrealistic, suggesting that a highly "selective" package of services care be targeted onto a more limited section of the population, such as children under five (Cueto, 2004). Aside from such disagreements over strategy, it soon became apparent that in most countries a comprehensive, community-based strategy based on rural areas would be difficult to sustain financially - given ever shrinking resources in the wake of the debt crisis and structural adjustment decade (Carrhill, 1994) - and politically, given urban bias (and the resulting concentration of resources onto hospitals and curative care), centralization of decision-making and resources in (often corrupt) bureaucracies, and donors' own reluctance to decentralize operations (Atkinson, Cohn, Ducci \& Gideon, 2005; Schmidt, 1995).

Even where the PHC model was successful in the early stages, it left the health sectors illprepared for the set of institutional changes around the sector that have occurred, and that have made the challenge of sustaining and deepening public health achievements complex. Two interrelated developments have had a particularly direct bearing on the position of the community clinic.

One is marketization. By the late 1980s, a fundamental shift in concepts regarding the role of the state - the 'Washington consensus' - had problematized the notion of state provision of services on a massive scale. While some poor countries have encouraged private provision, pressure to establish cost-recovery mechanisms - to commercialize public service provision, with corresponding reductions in budgeted inputs to the sector - was even more common (Sepehri, Chernomas \& Haroon, 2005). The second trend was towards public sector decentralization, one of the development mantras of the 1980s and 1990s (Manor, 1999; Bossert and Beauvais, 2002). Health services have become increasingly dependent on the financial and political support of local governments.

The twin pressures of marketization (often within declining public budgets) and decentralization - both parts of the shift away from a PHC to a 'health sector reform' model has had complex effects on the grassroots PHC infrastructure (Segall, 2003). Where this infrastructure was extensive, marketization and decentralization could reinforce patterns of decay and neglect in the physical maintenance of the clinics. Impacts on individual clinics were theoretically ambiguous: cost recovery might drive service quality levels higher, leading to further service utilization and cost recovery in a virtuous circle (Litvack and Bodart, 1999). Or user fees might lead to a downward spiral, providing a green light for unregulated charges being commandeered by salary-starved health workers, and killing off already low utilization of clinic services (Ensor, 2004). While analysts argued the plausibility of these different scenarios, case studies often suggested both effects were at work in different areas of the same country, reinforcing inequalities of coverage and outcome between regions, local governments and 
communities with the differential ability, capacity or willingness to fund PHC's grassroots network (Fritzen, 1999).

Effects at the level of aggregate population health outcomes were also mixed. Alarming declines were noted in some transitional contexts due to spectacular collapses of public health delivery systems, for example in parts of Eastern Europe and the former Soviet Union (WHO, 2000). Other countries - among them Vietnam - made continued improvements in population health indicators even while the organizational basis for health systems changed significantly. At the same time, few doubted that the impact on relatively poor households and regions of a country - those with the least capacity to play the cost recovery game, among other disadvantages - might be strongly negative. It was also clear that the complicated institutional landscapes, and growing performance and outcome inequalities, of developing country health sectors would strain the capacity of health authorities to achieve overall policy coherence and effective implementation (Sepehri, Chernomas \& Haroon, 2005).

\section{The case of Vietnam}

Vietnam presents a good example of the challenges associated with making an extensive PHC network function successfully in a changing public sector environment. As in other communist countries (China, North Korea, Cuba), the overwhelmingly rural populace in Vietnam was collectivized into specialized work brigades, aggregated into communes that organized both production and consumption. Despite experiencing decades of war, the government in the North invested heavily in a PHC strategy centered on Commune Health Centers (CHCs) as the corresponding organizational basis for boosting the percentage of the population with access to simple curative and preventive health services (Tran, 2004). The strategy was undoubtedly successful in some important ways: by the mid-1980s, Vietnamese enjoyed a life expectancy among the highest and infant mortality rates (IMR) among the lowest, for a least developed country (LDC) (Nguyen, 1997).

One effect of the economic stagnation of the early 1980's was the weakening of commitment to social mobilization and equity. Neo-Stalinist forms of political organization were paralleled in the health sector by renewed emphasis on curative medical education and on fiscal allocations micro-managed by the center. In fact, by the time market-oriented reforms began in 1986, the health sector showed the same pronounced orientation toward curative care seen in other countries. About 80 percent of the national health budget was devoted to curative care, primarily in central and provincial hospitals (Fritzen, 1999).

The transition to a market economy exacted a further toll on the health sector, and specifically on the grassroots PHC infrastructure. Immediately following the introduction of market reforms in 1986, the situation deteriorated sharply - health workers were not paid, drugs of unknown quality flooded the countryside, and commune clinics lost their organizational and 
economic support from agricultural cooperatives. As late as 1992, the World Bank reported a "major resurgence" of malaria in the Northern Upland region and in areas bordering Cambodia, presumably caused by the scaling back of DDT spraying. Malnutrition rates increased even as Vietnam became the world's third largest exporter of rice (World Bank, 1992).

By the mid-1990s, however, there were persuasive reasons for Vietnam's health planners to feel optimistic. No marked decline in public health indicators occurred over the transition period. This success was thanks to both the tonic effects of broad-based economic growth: incomes were up and people were eating better - and to the recovery of some stability in the organizational and fiscal basis for health activities. Real per capita expenditure on the health sector stabilized by 1993, then increased marginally as a share of a rapidly growing GDP (World Bank and others, 2001). In 1996, the salaries of a quota of personnel from local clinics were incorporated into the national budget, allowing the introduction of some organizational discipline (Fritzen, 1999). And expenditures on targeted 'national programs' in areas such as malaria and TB-control were greatly increased, leading morbidity from both diseases to decline markedly in the late 1990s (World Bank and others, 2001).

Two major problems - equity and quality - have consistently directed attention to the underbelly of this apparent success story. Continuing disparities in health outcome and coverage indicators are apparent, and can become politically sensitive given the government's formal commitment to socialist-inspired equity. Infant mortality rates, for instance, have declined rapidly in several regions of the country over the 1990s, but remained stagnant in the central region; the urban-rural gap in infant mortality has increased significantly (Poverty Task Force, 2001:4). Utilization differentials are even more striking, and go to the heart of the problem for the PHC network. For example, while every commune in Vietnam - over 11,000 - has a commune health clinic, around a quarter of expectant mothers in the Northern Uplands and Central Highlands regions of the country had no contact with any trained medical provider throughout their pregnancy in 2001 (SRVN 2005:40).

The quality of health care provided at all levels of the system is another point of growing concern. At the grassroots, the state of infrastructure, training, accountability and drugavailability - among other attributes of quality - vary significantly in ways explored below. Throughout the referral chain, perceptions of quality are strongly influenced by the gap between system capacities and the rising expectations of an increasingly urbanized and affluent population. Extremely high rates of self-treatment when ill (i.e. purchasing drugs without a prescription at pharmacies) serve as another indicator of coverage and quality problems (World Bank and others, 2001).

The 'steering' of the system by health authorities over the transition period has drawn mixed reviews. While the health sector had weathered the storm of institutional changes in the early transition, already in 1994 Chen and Hiebert painted a pessimistic scenario of "policy drift" in 
Vietnam's health sector, in which "deteriorating public assets could be increasingly commandeered by a poorly-paid public cadre for private purposes, bringing the bureaucracy, inefficiency and unresponsiveness of the public sector together with the inequity, ineffectiveness and social damage of the private sector" (Chen and Hiebert 1994:5). Health planners have had great difficulty constructing a coherent framework for regulating the emerging private sector and the public-sector wide commercialization of services (Ensor, 2004; Sepehri, Chernomas \& Haroon, 2005). In a remarkable finding that generated much controversy in Vietnam, the World Health Organization in 2000 ranked Vietnam (and China) near dead last - 187 of 191 countries in terms of "fairness of financial contribution" in the health sector (WHO, 2000). Vietnamese officials found fault in the method of WHO's calculation, but there is no question that barriers to effective utilization for the poor, and to acceptable levels of quality for the non-poor, remain significant.

\section{The National Health Support Project}

Against this changing institutional and policy backdrop, the problem of whether and how to revitalize Vietnam's vast network of community health clinics - the bulwark on which the twin goals of health equity and efficient coverage had previously been based - was thus never far from the frontlines of the debate. The paper turns now to the analysis of one of the critical elements in the revitalization plan, in the form of a major World Bank-supported effort to rebuild the grassroots infrastructure - the National Health Support Project (NHSP).

The dropping of the economic embargo by the United States against Vietnam in 1994 paved the way for the entry of multilateral financial institutions such as the World Bank, which initiated its first loan shortly thereafter. The World Bank has since 1993 committed US\$5 billion in grants and loans to Vietnam (www.worldbank.org.vn, accessed July 31, 2006). The twin projects which launched World Bank cooperation in the health sector were the NHSP and its sister project, the Population and Family Planning Project (PFPP). Encompassing a total investment of \$150 million in thirty of Vietnam's poorest provinces, the NHSP and PFPP together represented a substantial percentage of the total capital expenditure in the health sector over this period at district and commune levels. The NHSP itself was implemented from late 1996 to September 2003 with a total approved credit of \$101 million (of which approximately $75 \%$ had been disbursed as of June 2003) and several additional million in grants coming from Dutch and Swedish bilateral aid. The core component of the project was ambitiously subtitled "investing in an essential infrastructure for delivering public health services in Viet Nam", for which investment totaled approximately US\$70 million. Its objective was to "provide high quality, reliable primary health care on a sustainable basis in 16 poorer provinces” (World Bank, 1995). 


\section{Hypotheses and data}

The NHSP's design document (World Bank and Ministry of Health 1995) paints an overall picture of "a public health care sector which has reached a crossroads. Basic primary health care interventions of a preventive or palliative nature are being delivered, but coverage is still well below satisfactory levels and the quality of services is uncertain” (World Bank, 1995:23). The project's response was primarily to finance the reconstruction or upgrading of over 2,200 health clinics, and to provide the centers with a set of basic drugs and medical equipment. It was, as explored below, heavily 'supply-driven'. Testing the assumptions and hypotheses expressed in the NHSP's analysis of the health sector - contained largely in its design document and donor Aide Memoirs produced over the course of the project - elucidates the strengths and limitations of Vietnam's strategy for PHC revitalization over this period.

The project's design posited that infrastructural investments would have the following specific effects, which can be considered as three group of hypotheses for this study, roughly corresponding in the evaluation literature to project inputs, outputs and outcomes.

“Inputs” hypotheses:

H1. Investments in the grassroots infrastructure would lead to considerably enhanced capabilities of the CHCs

“Outputs” hypotheses:

H2: Substantially improved health centers and worker knowledge would have positive effects on treatment quality, supervision and management of the health centers, staff morale, the commitment of local authorities to funding the health centers, and the perception of PHC quality on the part of the rural population.

“Outcomes” hypotheses:

H3: The enhanced capabilities and performance of these health sectors would lead: (i) to enhanced utilization of the centers for basic curative services, which would disproportionately benefit the poor; and (ii) to enhanced capacities of the centers to perform preventive service functions.

This paper draws on two sources to test these hypotheses. The first is the use of the comprehensive Vietnam National Health Survey (VNHS), conducted over several months in 2001-2. It was implemented in over one thousand project and non-project communes nationwide. Comprising integrated commune-level, facility-based, health- worker and household surveys, the database allows assessment of several indicator- clusters highly relevant to the evaluation of the NHSP, including:

$\square$ Project Outputs, such as the state of the infrastructure and availability of essential drugs, drawing on the facility and practitioner questionnaires. 
- Strength of other PHC components, such as budget allocations to the clinics and district supervision patterns, drawing on the facility and commune leader questionnaires.

Clinic coverage and quality indicators, such as availability of services at the center and actual utilization of the clinics for different services, drawing on the facility and household questionnaires.

Some 88 communes covered by the survey's two-stage stratified sample had clinics that had completed NHSP-financed reconstruction prior to the date of the VNHS interviews. These 88 clinics, distributed over 15 of the 17 project provinces, comprise $4 \%$ of the some 2,200 clinics eventually supported under the project.

Use of the VNHS allows for systematic comparisons between project and matched nonproject communes. A propensity score matching model was employed to find the closest comparison group from the sample of non-project communes in the VNHS. Table 1 shows the indicators used to construct the sample and the actual results obtained with the current set of matching communes. These indicators reflect exogenous factors that influence key outcome indicators but are themselves unlikely to be affected by the project. Here, they fall into three categories: a) basic physical and locational characteristics; b) socio-economic characteristics of the population; c) government programs supplied (not in the health sector); and d) access to alternative providers of health services. Statistical tests for significance confirm visual inspection: project and 'matching' communes are not significantly different in terms of any of the criteria used to construct the matching commune sample. They offer a remarkably similar profile. 
Table 1

Comparison of characteristics of project and matching communes used in quantitative analysis of VNHS

\begin{tabular}{|c|c|c|}
\hline & Project communes & Matching communes \\
\hline Number of communes in group & 88 & 227 \\
\hline$\%$ Ethnic minority households & 15.9 & 18.1 \\
\hline \% with hospital within commune boundaries & 10.2 & 10.1 \\
\hline $\begin{array}{l}\text { \% of communes with Hunger Eradication and Poverty } \\
\text { Reduction Program (HEPR) }\end{array}$ & 70.5 & 76.7 \\
\hline $\begin{array}{l}\text { \% of communes with road available to commune } \\
\text { People’s Committee }\end{array}$ & 95.5 & 96.9 \\
\hline Km to district hospital & 9 & 11 \\
\hline $\begin{array}{l}\text { Share of poor households (according to Ministry of } \\
\text { Labor, Invalids and Social Affairs standards) }\end{array}$ & 16.7 & 17 \\
\hline Commune has Primary Health Care Committee? & 88.6 & 86.8 \\
\hline $\begin{array}{l}\text { Mean number of private practitioners in commune } \\
\text { (traditional medicine) }\end{array}$ & 1.29 & 1.25 \\
\hline $\begin{array}{l}\text { Mean number of private practitioners in commune } \\
\text { (Western medicine) }\end{array}$ & 2.82 & 3 \\
\hline Commune has Polyclinic & 14.7 & 13.2 \\
\hline $\begin{array}{l}\text { \% of communes on government's "Poorest Communes" } \\
\text { list }\end{array}$ & 9.1 & 15.4 \\
\hline Mean area, ha & 3947 & 3447 \\
\hline \multicolumn{3}{|l|}{ Topography: } \\
\hline Coastal & 7.9 & 7.9 \\
\hline Delta & 42.1 & 39.2 \\
\hline Midland & 14.8 & 10.5 \\
\hline Low mountains & 18.2 & 22 \\
\hline High mountains & 17.1 & 20.3 \\
\hline
\end{tabular}

The second method employed was fieldwork in four provinces selected for their regional representativeness - Son La, Quang Tri, Phu Yen, Soc Trang - in which a total of 8 districts and 16 commune health centers (all project based) were visited by a team of five researchers for two days each in 2003. The fieldwork involved semi-structured and open-ended interviews with provincial and district health officials, clinic personnel and focus group discussions with users and non-users of clinic services in the community. The research aimed at the direct observation and assessment of management practices in the center, the strength of preventive health program implementation, and patterns underlying utilization of clinic services in the broader context of district health systems. 
The research strategy employed has limitations that deserve highlighting. The propensity score matching method is a second-best substitute for an evaluation design rooted in a before/after comparison of panel data. Information systems in the NHSP were acknowledged by project supervisors to be weak, and in practice no useable baseline data was created or stored. And the fact that 'matching' communes may have received upgrading assistance from nonproject sources (though none likely to be as comprehensive as that provided by the NHSP) implies that the magnitude of differences between project and matching communes may be somewhat understated.

\section{Results}

\section{H1: Effect on infrastructure quality}

One precondition for the project to have an impact is that the infrastructure itself be significantly upgraded. This may appear overly obvious, but corruption, inefficient implementation and poorly conceived operation and maintenance mechanisms could all theoretically blunt the immediately visible impact of the project on infrastructure quality.

Approximately 2,200 clinics in 17 provinces were upgraded or newly constructed by the project. In comparison with matching communes (most of which also received significant infrastructure investments since 1996) - Table 2 suggests the quality of CHC infrastructure is higher along a number of indicators, although in many cases only modestly so. Virtually all project-invested clinics are built solid, have rooms for consultation, immunization, birthing and family planning provision, and toilets. More significantly, a greater percentage of projects than matching clinics have appropriate hand-washing facilities, more sanitary toilets and a source of clean water on the premises. Taken together, these basic characteristics suggest that project clinics have improved capabilities to perform basic functions, in comparison with matching clinics.

On the other hand, Table 2 suggests that clinics that had been built with project funds over two years before the VNHS interviews actually had a higher need for repairs than matching communes (82\% compared with 72\%). Systems for the actual maintenance and repair of CHC facilities are, by implication, likely to be no better in project than in non-project areas, with important negative consequences for the long-term sustainability of the investments. This finding is consistent with observations from the field. Quality control in project-financed construction was generally inadequate and the design of the project neglected sustainability considerations. 
Table 2

Infrastructure characteristics in project and matching communes (\% of CHCs)

\begin{tabular}{|l|c|c|c|c|c|}
\hline & $\mathrm{P}\left(^{*}\right)$ & \multicolumn{3}{|c|}{ Project - invested communes } & \multirow{2}{*}{$\begin{array}{c}\text { Matching } \\
\text { communes }\end{array}$} \\
\hline Indicator & & & $\begin{array}{c}\text { Rebuilt more } \\
\text { than 2 years } \\
\text { prior to survey }\end{array}$ & $\begin{array}{c}\text { Rebuilt up to 2 } \\
\text { years prior to } \\
\text { survey }\end{array}$ & \\
\hline $\mathrm{N}$ & & 88 & 44 & 44 & 227 \\
\hline Built solid (b2=1 $\mid \mathrm{b} 2==2)$ & & 100 & 100 & 100 & 96 \\
\hline Without need of repair & 0.017 & 25 & 14 & 36 & 14 \\
\hline Needs two or more repairs & & 76 & 82 & 68 & 78 \\
\hline Has electricity & & 92 & 89 & 96 & 94 \\
\hline $\begin{array}{l}\text { Has clean water source on } \\
\text { premise }\end{array}$ & & 86 & 98 & 75 & 77 \\
\hline CHC has a toilet & 0.016 & 98 & 100 & 96 & 89 \\
\hline (if yes): Toilet is sanitary & 0.008 & 83 & 79 & 88 & 67 \\
\hline $\begin{array}{l}\text { General condition of CHC } \\
\text { assessed by surveyor as } \\
\text { clean }\end{array}$ & & & & & 75 \\
\hline
\end{tabular}

* P refers to significance level based on a two-sided t-test for hypothesis that the project (all) and matching commune means are the same. Only reported here if $p<.05$.

\section{H3: Impacts on utilization and preventive service quality}

This and the following section look at the overall outcomes that might be attributed to the upgraded infrastructure, before looking at the causal pathways that might explain such outcomes.

Utilization. One key outcome assumed and desired by the project was increase in the utilization of the clinics. Table 3 suggests that both inpatient and outpatient rates in project clinics are marginally higher than those in matching communes, although the effect is only statistically significant for outpatient visits. When disaggregated by socio-economic characteristics (table 4), an interesting pattern emerges. Results in matching communes confirm what is commonly posited by PHC strategists in Vietnam and elsewhere - grassroots clinics are more heavily utilized by the poor, with the non-poor 'fleeing' to the comparative quality of other providers, either private or higher up the referral chain. Projects with reconstructed centers are being used more heavily, not by the very poor (bottom quintile of households ranked in terms of per capita expenditure) but by all other quintiles, including the richest. This finding suggests a substitution effect, whereby the non-poor are considering the upgraded clinics to be of greater quality than before and are substituting these clinics for (more expensive and possibly more remote) alternatives. It also raises the question of why utilization remains unchanged for the very poor, to which the paper returns later. 
Table 3

Basic data on utilization of CHC and District Hospitals, and referral function of CHCs, in project and matching areas

\begin{tabular}{|l|c|c|}
\hline & $\begin{array}{l}\text { All project } \\
\mathrm{N}=88\end{array}$ & $\begin{array}{l}\text { matching } \\
\mathrm{N}=217\end{array}$ \\
\hline Inpatients at CHC per 1000 interviewees in past 12 months & 24.5 & 18.4 \\
\hline Percentage of all inpatients that were inpatients of the CHC & 13.8 & 12.2 \\
\hline $\begin{array}{l}\text { Outpatients at CHC per 1000 interviewees in past 12 } \\
\text { months }\end{array}$ & $983.8^{* * *}$ & 732.3 \\
\hline Percentage of all outpatients that went to CHC & $24.5^{* * *}$ & 18.4 \\
\hline Percentage of self-medication in all health seeking behavior & $71.6^{* * *}$ & 74.9 \\
\hline $\begin{array}{l}\text { Percentage of those with illness who do not go for any } \\
\text { consultations }\end{array}$ & $71.8^{* * *}$ & 75.2 \\
\hline
\end{tabular}

$*=$ two-sided $t$-test for difference in means significant at $p<.10$ level; $* *<.05 ; * * *<.01 ;$ outpatient and inpatient rates are visits per 1000 households interviewed in VNHS.

\section{Table 4}

Utilization of health services by socioeconomic characteristics in project and matching communes

\begin{tabular}{|l|c|c|c|c|}
\hline & \multicolumn{2}{|c|}{ Outpatient } & \multicolumn{2}{c|}{ Inpatient } \\
\hline & Project & Matching & Project & Matching \\
\hline & $\mathrm{N}=835$ & $\mathrm{~N}=1566$ & $\mathrm{~N}=111$ & $\mathrm{~N}=228$ \\
\hline Expenditure quintile: & & & & 34.7 \\
\hline Poorest & 1793.1 & 1754.9 & $47.2^{* *}$ & 26.2 \\
\hline 2 & $1965.7^{* * *}$ & 1660.7 & $40.4^{* * *}$ & 24.9 \\
\hline 3 & $2063.3^{* * *}$ & 1542.6 & $53.1^{* * *}$ & 38.4 \\
\hline 4 & $1770.8^{* * *}$ & 1160.1 & $70.4^{* *}$ & 18.8 \\
\hline Richest & $1625.5^{* * *}$ & 807.4 & $80.8^{* *}$ & \\
\hline
\end{tabular}

$*=$ two-sided $t$-test for difference in means significant at $p<.10$ level; **<.05; ***<.01; outpatient and inpatient rates are visits per 1000 households interviewed in VNHS.

Preventive service quality. To what extent can investments in infrastructure be expected to have an impact in the area of preventive services, such as implementation of the national programs combating tuberculosis and malaria? The field assessment teams found evidence of an 
increase in the effectiveness of targeted national programs in project communes over the previous five years, some portion of which might be traced to project investments and their indirect impacts. Newly constructed health center appeared to serve as more effective command centers for preventive service programs. Better infrastructure appears to have created better working conditions and improved the morale of commune health staff, while a basic equipment package provided to paraprofessional outreach workers may have improved their sense of professionalism, leading to positive effects on maternal and child immunization activities. Importantly, however, the assessment suggested that the magnitude of these effects was weaker in poorer localities surveyed; the project appeared to fail to boost the quality of preventive health services where the chain of implementation was weakest.

How does this assessment from the field mesh with results from the VNHS, which adds the structured comparison with matching communes to the picture? A basic review (not shown here) finds there are only marginal differences between project and non-project areas along almost all of the indicators relating to preventive health service quality, including no difference in the number of programs which the clinics report implementing, and a marginal difference in the number of contacts reported by households with national programs. The period in question witnessed extensive parallel investments in vertical health program delivery systems that have been assessed as successful nation-wide, and it is these investments that probably account for the bulk of improved performance noted by the field assessment teams. The fact that the network is still weakest in the poorest areas of the country was also underlined by the statistical analysis, and raises broader concerns to which the paper returns in the conclusion.

\section{H2: Explaining the impacts: the role of institutional quality}

Central to project's supply-side approach was an often repeated, but vaguely defined assumption that it would affect worker morale and commitment. Fieldwork findings were used to develop a typology of different pressures observed - weakly or strongly, singly or jointly - in the 16 communes surveyed. Figure 1 summarizes the results. Pressures for performance may come from five potential sources:

Mechanism \#1: Users, who - to the extent they are sufficiently empowered with information on their rights and the quality of services and enjoy a range of choices - can 'vote with their feet' and patronize the most responsive providers. Their influence is heightened as the fees raised from them are an important source of revenue to the $\mathrm{CHC}$.

Mechanism \#2: The private sector (and commercialized public sector hospitals) provide in theory competitive pressures on $\mathrm{CHC}$ as all are competing for the same group of potential patients.

Mechanism \#3: The political authorities who in theory can hold clinics responsible for meeting minimum standards may provide supplemental funding and keep closer tabs on the centers. 
Mechanism \#4: Technical authorities, i.e. the district health center, responsible for supervising all technical aspects of clinic work, may step up supervision of upgraded centers.

Mechanism \#5: Internal sources of motivation, such as a sense of professionalism or public service, may be enhanced by a range of factors, including better working conditions.

This figure presents only a hypothetical set of pressures. The most outstanding finding from the field assessment is that there is significant variation in the strength of the mechanisms in the localities surveyed. In the best cases, where several of these mechanisms are operative to a significant degree, clinics enjoyed the best observed outcomes in terms of curative and preventive health quality. Yet some communes surveyed, particularly in mountainous localities, suffered from most of these mechanisms simultaneously failing to function effectively. These were communes where:

Users were reluctant to complain about clinic performance.

There was little or no competitive pressure from the private sector, or the pressure was in fact dysfunctional as clinic workers were privately providing services that could have been captured by the center itself.

Commune authorities evinced no particular interest in the workings of the CHC.

District supervision was episodic, focused on numerical targets rather than technical support.

The bulk of communes fell somewhere in between the two poles just described.

Several project interventions assumed (generally without analysis) the existence of, and/or sought to reinforce, the accountability mechanisms described above. At least four specific effects on the institutional environment (hypothesis two) were posited by project planners, and can be broken out:

H2: Building 'shiny new' CHC facilities will improve:

i) health-worker morale [mechanism 5 in figure 1],

ii) commitment of the local authorities to the health sector [making use of mechanism 3]; and, via these two impacts, to

iii) the improved supervision and management of the centers [mechanism 4]; all of which should culminate in

iv) improved community perceptions of PHC quality [mechanism 1].

Each of these potential impacts is briefly examined below.

H2i: Impact of project investments on staff morale. Evidence from the field assessment team is strong on this point. Improvements to $\mathrm{CHC}$ facilities were highly appreciated by the staff, who reported working with greater enthusiasm in more comfortable surroundings. Many daily tasks such as maintaining cleanliness, drawing water, filing paperwork and attending to multiple patients in different examination rooms are easier to perform by better infrastructure. The fact that facilities were maintained in a significantly cleaner state in project, than in matching communes (see table 1) provides indirect evidence for this effect on morale. 
Figure 1

Pressures and incentives underpinning CHC performance: A framework

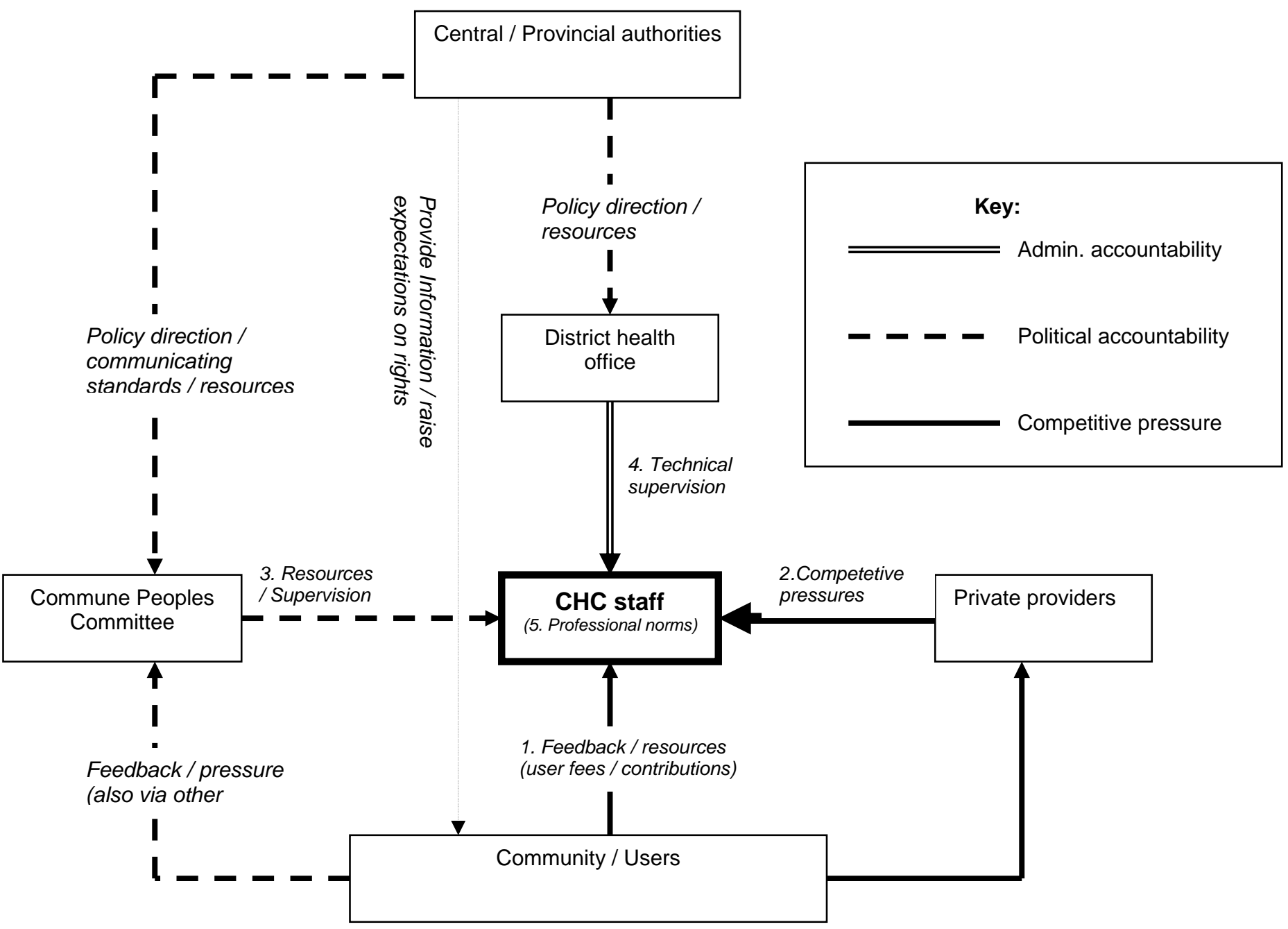

H2ii: Impact of project investments on commitment of local authorities. Commune-level political authorities could in theory be called upon to perform a range of functions, including actively intervening to ensure high service delivery standards in cases of resident complaints, coordinating inter-sectoral activities (such as health checkups in schools), and directly supplementing clinic budgets directly. While all of these functions were observed in some communes during fieldwork, the indicator of 'local authority commitment' that most strongly influenced clinic service quality in practice was budget supplementation. Fieldwork findings demonstrate significant variation in the degree to which commune authorities could supplement clinic budgets, and VNHS findings confirm this. Yet these variations were in practice 
completely uncorrelated with the presence of the project. In other words, contrary to the project hypothesis, upgrading the PHC infrastructure did not appear to change patterns of local 'political will' towards clinic functions.

H2(iii): Project impact on management and supervision quality. Evidence of a strong project effect on the management quality of the centers is not evident in fieldwork communes, given huge variations observed in practice within the project area. Fieldwork evidence suggests that clinics were most utilized, best maintained and in general had the highest impact on PHC quality in those areas that were already well managed prior to NHSP investments. This finding is confirmed when examining the VNHS data, in which there is no statistically significant difference in several proxies for management quality (such as maintaining accessible clinic hours, outreach to sick patient's homes, frequency of private sector provider supervision, and maintaining good records).

In addition, no difference was found in the supervisory frequency or scope of inspections of district officers in project and matching areas. Changing supervisory behavior in the absence of changing incentives and capacities is likely to be nearly impossible. Such patterns are highly dependent on the existing quality of institutional environment, such as the demand on the part of the political authorities for high quality PHC to be provided and hence greater pressure on the district personnel to intervene to maintain minimum standards.

H2(iv): Impact of project investments on community perceptions of facility quality. Community members rate the quality of care to be significantly higher in project compared to matching communes, although fieldwork results suggest their perceptions vary significantly within the project area as well. A composite indicator was calculated based on a range of questions posed to those who had utilized CHC outpatient and inpatient services. These questions asked respondents to assess service quality along a number of criteria: availability of modern equipment, knowledgeableness of staff, waiting time, paperwork requirements and others. The results of a statistical comparison (not shown here) suggest that users in communes with upgraded centers find service quality to be marginally better than those in the matching communes, in an effect that is modest but statistically significant.

Overall, evidence above points to the conclusion that the supply-oriented NHSP is unlikely to have had a consistent independent impact on local institutional quality, although it might have been an enabling factor in areas that were already supportive of strong PHC performance. However, the evidence does support the converse relationship - of institutional quality affecting project output quality - as there is often a strong correlation between different indicators underpinning institutional quality, such as commune budget commitments to clinics, intensity of district supervision and clinic management quality. 


\section{Discussion}

In Vietnam, extending the theoretical coverage of the rural population to basic health services, via a network of public clinics, has traditionally been strength of the sector. There is strong evidence that the country's health sector has not only emerged from serious organizational disruption suffered during the early transition to a market economy, but has solidified and improved the quality of this network (NCSSH, 2001). Whereas previously, a clinic providing 'coverage' to a commune population might have been understaffed, unequipped and in a facility on the verge of physical collapse, such cases are increasingly rare even in remote areas. The NHSP and associated projects have made a significant 'supply-side' contribution to this rebound.

Boosting the quality of service coverage at the commune and district levels was appropriate from an equity perspective. Investments in the grassroots PHC network are relatively pro-poor: utilization of the CHC network is remarkably even among population groups, unlike that of district (let alone higher level) hospital services (World Bank and others, 2001), and the rural poor also benefit disproportionately from public health interventions implemented by local public clinics.

The revitalization of the grassroots public health infrastructure remains uneven, however. As shown above, utilization of clinic curative services by the poorest segment of the rural population did not rise significantly due to project infrastructural upgrading; barriers on the demand side, and in terms of the effective implementation of fee exemption mechanisms for the poor, remain binding. And despite substantial supply-side investments, a substantial number of clinics are failing to achieve or sustain basic quality standards. Since these communes typically have a high proportion of ethnic minorities and/or poor households, such failure is having serious equity consequences. Infrastructural disparities can be reduced with sufficient investment theoretical 'coverage' can be improved - but the experience of the NHSP suggests the persistence of an 'equity gap' that is not bridgeable by a supply-driven, facility-based project and strategy alone.

The situation of Vietnam in this regard is not unique. It is relevant to a range of countries where previous PHC-oriented strategies - whether half-hearted or fully implemented - have bequeathed a widespread network of public health clinics throughout the countryside. Where such infrastructure is found, it is often in a state of disrepair and disorganization in part because the broader public sector reform process has rendered the organizational and fiscal basis for previous sector strategies ineffective, obsolete. Yet this paper is not meant to suggest that improvements to the 'supply side' of the PHC network are not necessary in such cases; where important, irreplaceable public health roles are being played by these centers, such investment is essential. The Vietnamese case does suggest four areas in which strategies for the revitalizing PHC strategies will need to be rethought in an era of 'health sector reform', with its 
accompanying tendencies towards decentralization, marketization of services and growing access inequalities (Hall and Taylor, 2003).

First, the specific roles and appropriate resources commanded by public clinics and other aspects of the PHC network at the grassroots will need to be redefined within a broader context of health and public sector reforms. Formulating PHC strategies in isolation of such trends as decentralization and marketization of public services is a key factor underlying the failure of PHC systems in many countries. Health planners will need to examine their assumptions concerning the equity implications of allowing the public health network to be thrown onto its own resources.

Two examples may help underline the point. As explored above, grassroots clinics in most settings have the dual role of providing simple curative care and serving as the organizational outposts for preventive health programs. The impacts of health sector reform on clinics have largely been to make recurrent financing for curative services problematic and uneven across localities. The dynamic effects of such developments on the preventive health functions - via staff morale or supplemental local funding for such funding out of clinic budgets, for instance are often ignored, particularly since preventive programs have different (vertical) planning and budgeting systems for which the grassroots network is taken as given, as just an implementing node. A second example might be the assumption embedded in many reforms that the poor can be effectively targeted with exemptions to user fees or with low-cost health insurance. In practice, such targeting demands considerable capacity at the grassroots - capacities that are often being undermined by the very reforms necessitating better targeting. Health sector reform approaches cannot afford to take a naïvely optimistic approach to the issue of equity and grassroots capacity to sustain effective coverage for the rural population As in Vietnam, the challenge of ensuring equitable access to basic health services for the poorest segments of the population, and in the poorest regions of large countries, is one for which the grassroots infrastructure of PHC is likely to remain essential.

A second implication of the analysis is the need to work out effective institutional arrangements for health sector decentralization (Fritzen, 1999). Utilization rates for public clinics are diverse at the grassroots for a host of reasons that can only partly be influenced by supply-side factors. Rather than trying to have one model for the services that such clinics are equipped and financed to deliver to minimum standards, the attempt should be to maximize the returns - from both equity and efficiency perspectives - on scarce public investment in the health sector. To take the Vietnamese case as an example, data suggest that a wide range of rural clinics have virtually no inpatient visits. Yet, newly propagated national standards by the Ministry of Health for all commune clinics to the year 2010 emphasize larger facilities that would be more costly to construct and maintain and which would not necessarily reverse locality-specific patterns of utilization. Just as urban clinics are constructed to different specifications and play a different role in urban health delivery from those in rural areas, greater 
diversity in health planning is needed for rural areas. Such diversity may extend to include models that are region- or location-specific (differentiating between clinics based on how far they are located from district or provincial referral hospitals, for instance), and a structured menu of investment options that can be placed under the discretion of provincial and district authorities to adjust periodically.

A final implication of the analysis is to reinforce recent calls in the literature (Franco, Bennett \& Kanfer, 2002; Atkinson, Cohn, Ducci \& Gideon, 2003; World Bank, 2004; Ensor and Ronoh, 2005) for further work and attention to strengthening the institutional environment underpinning health clinic performance. A framework for analyzing the set of pressures and incentives felt by clinic personnel and various other key stakeholders is proposed in this paper (figure 1 above). Efforts to strengthen the grassroots PHC infrastructure will be unsustainable if they are not accompanied by, and integrated with, efforts to improve local management capacities, incentives, worker morale, skills and effective avenues of accountability (technical, political and end user-oriented).

This discussion of strategies for revitalizing the grassroots PHC infrastructure is in some ways timely. The publicly-stated commitment of developing country governments and donors to achieving improved health outcomes for the poor has if anything been boosted by the prominence of the Millennium Development Goals, as well as the awareness that effective responses to existing and potential transnational epidemics, such as the H5N1 virus, will depend in part on capacities at the bottom rung of health systems. The infrastructural inheritance of early PHC adopting countries has not yet outlived its usefulness. But the strategies underpinning its deployment are in many settings showing their age, and will need to be adjusted in the context of more dominant streams of health sector reform.

\section{References}

Atkinson, S., Cohn, A., Ducci, M., Gideon, J. Implementation of promotion and prevention activities in decentralized health systems: comparative case studies from Chile and Brazil. Health Promotion International 20(2):167-175.

Bossert, TJ and JC Beauvais (2002) Decentralization of health systems in Ghana, Zambia, Uganda and the Philippines: a comparative analysis of decision space. Health Policy and Planning 17(1):14-31.

Carrhill, R. (1994) Efficiency and equity implications of the health-care reforms. Social Science \& Medicine 39(9): 1189-1201.

Chen, L. and L. Hiebert (1994). From Socialism to Private Markets: Vietnam's Health in Rapid Transition. Cambridge, MA, Harvard Center for Population and Development Studies.

Cueto, M. (2004) The origins of primary health care and selective primary health care. American Journal of Public Health. 94(11): 1864-1874. 
Ensor, T. (2004) Informal payments for health care in transition economies. Social Science and Medicine 58(2):237-246.

Ensor, T., Ronoh, J. (2005) Impact of organizational change on the delivery of reproductive services: a review of the literature. International Journal of Health Planning and Management 20(3):209-225.

Favin, M., Parlato, P., \& Kessler, S. (1984) Primary health care progress and problems. Public Health Review 12(3-4):272-8.

Franco L.M., Bennett, S., Kanfer, R. (2002) Health sector reform and public sector health worker motivation: a conceptual framework. Social Science and Medicine 54(8):1255-1266.

Fritzen, S. (1999) “Fiscal decentralization, disparities and innovation in Viet Nam's Health Sector”, in Litvack, J. and D. Rondinelli (eds.), Market Reform in Vietnam: Building Institutions for Development; Westport, CT: Quorum Books.

Hall, J., \& Taylor, R. (2003) Health for all beyond 2000: the demise of the Alma-Ata Declaration and primary health care in developing countries. Medical Journal of Australia 178(1):17-20.

Litvack, J.I., Bodart, C. (1993) User fees plus quality equals improved access to health-care: results of a field experiment in Cameroon. Social Science \& Medicine 37(3):369-383.

Manor, J. (1999) The Political Economy of Democratic Decentralization. Washington, DC: World Bank.

Mehrotra, S. (1997) "Social Development in High-Achieving Countries: Common Elements and Diversities" in Development with a Human Face: Experiences in Social Achievement and Economic Growth, Mehrotra, S. and R. Jolly (eds), Clarendon Press, Oxford

National Center for Social Sciences and Humanities [NCSSH] (2001). National human development report 2001: Doi moi and human development in Vietnam. The Political Publishing House, Hanoi.

Nguyen Nguyet Nga (1997). Health sector development and economic reform in a transitional economy: Vietnam 1989-1997. Ph.D. dissertation. University of Manchester.

Osteria, T. (1997) “Social Development in the Asian Region: Policy Issues and Challenges” in Ismael, J. and E. Hill (eds) Social Welfare and Social Development: Asian Experiences. Calgary: Detselig.

Poverty Task Force (2001) Localizing MDGs for poverty reduction in Viet Nam: Improving health status and reducing inequalities. http://www.worldbank.org.vn/strategy/cprs/pdf/HEALTH-E.PDF, accessed March 28, 2006.

Rigoli F., Dussault, G. (2003) The interface between health sector reform and human resources in health. Human Resources for Health 1(9).

Schmidt, G. (1995) Bridging the donor-decentralization gap - Rethinking incentives and institutional impacts in control-oriented bureaucracies. Studies in Comparative International Development 30(1):59-83.

Segall, M. (2003) District health systems in a neoliberal world: a review of five key policy areas. International Journal of Health Planning and Management 18:S5-S26. 
Sepehri A., Chernomas, R. Haroon AL. Penalizing patients and rewarding providers: User charges and health care utilization in Vietnam. Health Policy and Planning 2005; 20(2):9098

Socialist Republic of Vietnam (SRVN) (2005) Vietnam: Achieving the Millennium Development Goals. http://www.un.org.vn/undocs/mdg04/mdg04e.pdf, accessed July 15, 2006.

Socialist Republic of Vietnam [SRVN] and Donor Working Group on Public Expenditure Review (2000). "Managing public resources better: Public expenditure review 2000.” World Bank, Hanoi.

Tran, T. Community-based evidence about the health care system in rural Vietnam. Ph.D. dissertation 2004; The University of Newcastle, Australia.

World Bank (2004) World Development Report 2004: Making Services Work for the Poor. New York: Oxford University Press.

World Bank (1995). Project Appraisal Document: The National Health Support Project. Hanoi: Mimeo.

World Bank and Donor Working Group (2001). Growing healthy: A review of Vietnam's health sector. Hanoi: World Bank.

World Bank (1992) Viet Nam: Population, health and Nutrition Sector Review. Population and Human Resources Operation Division, Country Department I, East Asia and the Pacific Region. Washington, D.C.: The World Bank.

World Health Organization (2000) World Health Report 2000: Health Systems: Improving Performance. Geneva: World Health Organization. 